\title{
RESEARCH WORK OF THE NATURE CONSERVANCY
}

\begin{abstract}
A
$\mathrm{N}$ adjournment debate in the House of Commons on July 21, at which was discussed the research work of the Nature Conservancy, was opened by Mr. M. Kimball with an attack on the work of the Conservancy which showed a complete misunderstanding of the purposes and nature of the Conservancy. Nevertheless, the debate as a whole should prove a useful piece of publicity for the work of the Conservancy, which still lacks the resources necessary for an adequate publicity policy to remove misunderstandings such as those exemplified by Mr. Kimball's speech. On the matter of finance, it may be noted that, although several speakers commented on the inadequacy of the Conservancy's budget of no more than $£ 500,000$ a year, the Parliamentary Secretary for Science, Mr. D. Freeth, made no comment beyond saying that it is a matter for individual judgment whether the Conservancy's resources are too small.

Mr. Freeth, recalling the Director-General's description of the research programme as "a comprehensive attack on a range of ecological problems which are regarded as of fundamental significance for the advance of conservation", maintained that besides increasing scientific knowledge, the Conservancy's work is in the long run of great benefit to the nation. Of a staff of 250, 100 are scientists, and the Conservancy also maintains 40 postgraduate students working for doctorates in ecology and related sub. jects. It is, he insisted, a research council, and although it does its best to encourage interest in Nature and its conservation, this is not a primary purpose, and one has to recognize that many of the reserves are established to be sanctuaries for wild life, a purpose inconsistent with free access. The Conservancy welcomes at all its reserves scientists and university workers who have research to do which is likely to be of value. Mr. Freeth does not believe that there is overlapping with the work of other Government research organizations. There is considerable interlocking of personnel at a very high level, as well as on ad hoc committees, and the Select
\end{abstract}

Committee on Estimates which explored the question of relations with the Forestry Commission in 1958 found no evidence to justify a recommendation to transfer to the Commission some of the fundamental research now undertaken by the Conservancy. Much of the Conservancy's research is basic in character and not suitable for dissemination through the National Agricultural Advisory Service.

The Conservancy, Mr. Freeth pointed out, controls about 8,000 acres of woodland, and research here is essential: first, to provide representative examples of the more important ecological types in their earlier stages of development; secondly, to provide adequate areas of managed woodland which would otherwise be threatened by systems of management more concerned with profit-making; and thirdly, to provide specialized facilities for undisturbed research and long-term field-trials. Mr. Freeth specifically denied the suggestion that the Nature Conservancy has ever established the breeding of coypu. For publicity or educational campaigns, or the issue and enforcement of regulations, the Conservancy has to look, for example, to the Ministry of Agriculture or of Transport.

As regards liaison and co-operation with county naturalist trusts and other bodies of naturalists, Mr. Freeth pointed out that the Select Committee on Estimates was impressed with the argument that unique opportunities for research would be lost if the Conservaney did not acquire as soon as possible the whole of the 250,000 acres envisaged. At present, 88 reserves represent 177,000 acres, and $\mathrm{Mr}$. Freeth does not think it reasonable to delay proceedings merely because in a particular area a county organization has not been formed. He welcomed Mr. Kimball's praise of the Nature Conservation Corps, but to what was perhaps Mr. Kimball's most important point-. that for only half the reserves has a five-year management plan been established-he made no reply. If this is due simply to financial stringency, it is time that the Minister for Science-and Parliamentacted.

\section{SALMON AND FRESHWATER FISHING IN GREAT BRITAIN}

$\mathrm{R}$ ECENTLY the Committee on Salmon and Freshwater Fisheries produced a stimulating report in which are made several recommendations which may lead to some very necessary changes in freshwater fishery legislation."

Of major importance are the recommendations that the powers of the River Boards be extended. The report rightly appreciates that fishery problems are often localized and suggests that River Boards should be allowed to make by-laws to suit local conditions. Equally important are the recommendations that River Boards should have the power to demand accurate returns of catches from all licence holders. Clearly, adequate salmonid fishery conserva* Report of the Committee on Salmon and Freshwater Fisheries,
(Cmnd. 1350.) Pp. vili $+151+13$ plates. (London: H.M.S.O., 1961.) 8s. net. tion is greatly hampered by inaccurate returns of catches. As conservation to a large degree centres around re-stocking, it is obvious that the recommenda. tion that no person be permitted to stock his waters without the consent of the River Board is pertinent: there is much more to stocking than the mere planting of fish.

Some valuable recommendations are made on the control by River Boards of the obstructions to migratory fish, and of particular importance in this context is the suggestion that a River Board should have the power to prevent any diversion of water unless sufficient water is passed down the original channel to avoid damage to fisheries. Equally sound is the point made that old dams, sluices, or leats in poor condition should be repaired by the owners, or alternatively demolished. Overerowding in pools 
below unsurmountable weirs often results in dead fish during periods of high temperature and low water.

Pollution is dealt with admirably; and the suggestion that the Armer Committee's recommendations relating to the control of existing discharges should be extended to estuarine waters, should, if adopted, be highly beneficial to salmonid fisheries. I would like to see this control extended to all inshore waters.

The report stresses the need for more freshwater fishery research, and I am certain that the far too few freshwater-fishery biologists that are active in Britain will applaud the proposals that electric fishing and poisoning should be permitted for the purpose of scientific fishery research.

A report of this nature, which is of great interest not only to the $2 \frac{1}{2}$ million anglers but also to many industrialists, water undertakings and public bodies in Britain, will inevitably suffer much criticism. To a fishery biologist it suggests a beneficent revolution, but I find a few minor points of disagreement with the Committee. First, because only 2,000 netsmen are dependent, or partly dependent, on salmon fishing for their livelihood, because salmon anglers outnumber netsmen by about fifty to one and because anglers are of greater economic importance to River Boards, riparian owners, the tackle and tourist industry, I would recommend that netting be discontinued until salmon are much more plentiful. The netsmen should be adequately compensated. Secondly, I would recommend strongly that kelts should be preserved. As the report states, previously spawned fish form 5 per cent or more of salmon catches in the
United Kingdom and thus represent at least 15 tons of fish; it would need several expensive hatcheries to produce this weight of fish. Thirdly, I would prohibit angling for salmon after the first week of September; in most cases this would protect the gravid fish and dispense to a large extent with the need for an accurate definition of unclean fish as discussed in the report. Fourthly, I would advocate a close season for coarse fish and that this be suited to local conditions. In addition, I would make it illegal for fishermen to return coarse fish above the minimum size, as many coarse fisheries are vastly overstocked and consequently the fishes are stunted. Lastly, I feel that the report should have stressed more strongly the need for research on coarse fish and I would suggest that this should be carried out in a national laboratory. I am certain that the River Boards and the River Boards Association would find such an institution invaluable.

Despite these objections the report is of major importance. It rightly emphasizes the remarkable achievements of the River Boards and its suggestions for the extension of their powers or for extended use of existing powers are expert, moderate and reasonable, as are its recommendations for compensation or non-compensation of affected interests. Everyone who has at heart the interests not only of the fisheries but also of rivers and lakes and the country as a whole will watch impending legislation closely and pray that the recommendations of the report become law with a minimum of mutilation and, above all, a minimum of delay.
J. W. JONES

\title{
ELECTRIC CURRENTS ASSOCIATED WITH GEOMAGNETIC DISTURBANCES IN THE AURORAL ZONE
}

\author{
By Dr. F. J. SCRASE \\ Meteorological Office, London
}

\begin{abstract}
$\mathrm{T}$ HE electric current systems in the high atmosphere in high latitudes, especially along the auroral zones, are complex and variable. The normal networks of geomagnetic observatories suffice only to provide inferences of the broader features of these systems. With the view of their more detailed study, the Special Committee of the International Geophysical Year, at its Rome meeting in 1954, recommended that some observatories in auroral regions should be supplemented by two subsidiary stations, in directions at right angles and about $20 \mathrm{~km}$. from the main station, for the measurement of the horizontal space gradients of the magnetic elements.

In an article amplifying these recommendations, S. Chapman ${ }^{1}$ explained how knowledge of a disturbance in horizontal magnetic force produced by a horizontal current flowing directly overhead, together with the vertical gradient of the disturbance, will indicate the strength and height of the current separately. Since the divergence and curl of the magnetic field are both zero, the vertical gradients can be derived from the horizontal gradients.

In accordance with the recommendation of the Comité Spécial de l'Année Geophysique Internationale, two subsidiary stations equipped with Askania variographs were set up near the Meteoro-
\end{abstract}

logical Office Geophysical Observatory at Lerwick $\left(60^{\circ} 08^{\prime}\right.$ N., $01^{\circ} 11^{\prime}$ W. $)$ and were operated for part of the International Geophysical Year and its successor the International Geophysical Co-operation, 1957-59. One of the stations was at Aipleton, $26.7 \mathrm{~km}$. south-south-west of the main station and the other at Bridge of Walls, $22.3 \mathrm{~km}$. west-northwest. This article describes preliminary results of attempts to estimate the magnitude and position of the electric currents during some magnetically disturbed periods.

\section{Method of Analysis}

The disturbances selected for measurement were mostly those of the bay type of a few hours duration, but a few were sharp peaks of shorter duration. For each station the components of the disturbance vector were derived by measuring the maximum deviation with respect to an undisturbed part of the record shortly before the disturbance, or to the interpolated undisturbed value at the time of the maximum. It soon became evident that values of the horizontal space gradients derived from differences between records from the pairs of stations did not conform with the theoretical relationships between 